\title{
南方红壤区长期水土流失综合治理显著减少河流输沙——以鄱阳湖 流域赣江上游平江为例"
}

\author{
聂小飞 ${ }^{1,2,3 * *}$, 郑海金 ${ }^{1,2}$, 涂安国 ${ }^{1,2}$, 莫明浩 ${ }^{1,2}$, 宋月君 ${ }^{1,2}$,谢颂华 ${ }^{1,2}$,王 $飞^{3}$ \\ ( 1 : 江西省土壤侵蚀与防治重点实验室,南昌 330029) \\ $(2$ : 江西省水土保持科学研究院,南昌 330029$)$ \\ (3: 中国科学院教育部水土保持与生态环境研究中心,杨凌 712100)
}

\begin{abstract}
摘 要: 长时间序列水沙数据分析有助于科学评价流域尺度水土保持减流减沙效应, 为科学开展区域水土保持成效评估 提供实现路径. 本文选取南方红壤区水土保持工程最为集中、持续时间最长的典型流域——平江流域,基于 1975-2014 年的逐日降水量、流量、含沙量数据, 综合应用预置白 M-K 检验法、Theil-Sen 趋势度估计法、Pettitt 检验法与累积量斜率变 化率比较法, 开展河流水沙变化特征及归因分析, 揭示长期水土流失治理对河流水沙的影响. 结果表明: (1) 1975-2014 年平江年输沙量、汛期输沙量和非汛期输沙量均存在显著减少趋势, 年均减少率分别为 $2.38 \times 10^{4} 、 1.75 \times 10^{4}$ 和 $0.44 \times 10^{4}$ $\mathrm{t} / \mathrm{a}$, 汗期输沙量在流域开始实施系统水土流失治理时即发生突变, 而年输沙量和非汛期输沙量在系列国家水土保持重点 工程实施一段时间后方开始突变; (2) 流域长期水土保持显著减少平江输沙, 但对径流无显著影响, 重点治理期、治理后 期以水土保持为主的生态保护工程对输沙量减少的贡献均在 $94.0 \%$ 以上,且生态保护工程对汛期输沙量减少的贡献较非 汗期的更为突出; ( 3) 以水土保持为主的长期生态保护工程导致平江全年、汛期、非汗期输沙量分别减少 $59.3 \%$ 、60.7\% 和 $55.7 \%$; (4) 在剔除大型水利工程 (尤其是大中型水库) 建设影响后, 南方红壤区可以基于长时间序列水沙数据分析科学 评价流域尺度水土保持减流减沙效应. 研究结果可以为南方红壤区流域尺度水土保持减流减沙效应评价提供参考, 并有 望为区域系列国家生态保护与建设工程的布局和管理提供科学依据.
\end{abstract}

关键词: 径流量;输沙量;变化特征;归因分析;水土保持;鄱阳湖流域;赣江上游;平江

\section{Long-term soil and water conservation in red soil region of southern China significantly re- duced riverine sediment load: A case study of Pingjiang River in the upper reaches of Ganjiang River, Lake Poyang Basin*}

Nie Xiaofei ${ }^{1,2,3 * *}$, Zheng Haijin ${ }^{1,2}$, Tu Anguo ${ }^{1,2}$, Mo Minghao ${ }^{1,2}$, Song Yuejun ${ }^{1,2}$, Xie Songhua ${ }^{1,2}$ \& Wang $\mathrm{Fei}^{3}$

(1: Jiangxi Provincial Key Laboratory of Soil Erosion and Prevention, Nanchang 330029, P.R. China)

(2: Jiangxi Institute of Soil and Water Conservation, Nanchang 330029, P.R.China)

(3: Research Center of Soil and Water Conservation and Ecological Environment, Chinese Academy of Sciences and Ministry of Education, Yangling 712100, P.R.China)

Abstract: The analysis of water and sediment data with long time series is helpful for the scientific evaluation of flow and sediment reduction effect of watershed-scale soil and water conservation, and provides an effective method for the scientific evaluation of regional soil and water conservation effectiveness. The Pingjiang River Watershed in the upper reaches of Lake Poyang Basin, which is the typical watershed with the most concentrated and longest ecological protection engineering construction in the red soil region of southern China, was selected as the study area. Based on the daily rainfall, flow, and sediment concentration data of $1975-$

* 2020-05-13 收稿;2020-08-10 收修改稿.

国家自然科学基金项目 (41601297)、江西省青年基金项目 (20171BAB213022)、江西省水利厅科技项目 (201821ZDKT20,201820YBKT16,201820YBKT19) 和江西省博士后科研择优资助项目 (2019KY46) 联合资助.

** 通信作者;E-mail:xfnie85@163.com. 
2014, pre-whitening Mann-Kendall test, Theil-Sen trend analysis, Pettitt's test, and comparative method of the slope changing ratio of cumulative quantity were conducted. Variation characteristics of flow discharge and sediment load were analysed, major influencing factors were identified, their contribution rates to flow discharge and sediment load variation were quantified, and effects of long-term soil and water conservation on flow discharge and sediment load were revealed. The results showed that: (1) From 1975 to 2014 , sediment load of the whole year, flood season, and non-flood season all decreased significantly, with the yearly decreasing rate of $2.38 \times 10^{4}, 1.75 \times 10^{4}$, and $0.44 \times 10^{4} \mathrm{t} / \mathrm{a}$, respectively, and the mutation of flood sediment load occurred once the soil and water conservation project began, while the mutation of the whole year and non-flood sediment load didn't happen until most of soil and water conservation projects accomplished. (2) Long-term soil and water conservation in the watershed significantly reduced the sediment load in Pingjiang River, yet had no significant effect on runoff discharge. During both the key control period and post-control period, the contributions of ecological protection projects, which mainly focused on soil and water conservation, contribution rate to the reduction of sediment load were more than $94.0 \%$, while the contribution of ecological protection projects to the reduction of sediment transport in flood season was more than that in non-flood season. (3) Long-term ecological protection projects based on soil and water conservation resulted in a decrease of 59.3\% , 60.7\% , and 55.7\% for sediment load of Pingjiang River during annual, flood, and non-flood period, respectively. (4) After excluding the impact of large-scale hydraulic engineering construction projects, especially large and medium-sized reservoirs construction, the effect on flow and sediment reduction in the watershed scale of soil and water conservation could be scientifically evaluated based on the analysis of long-term flow discharge and sediment load data in the red soil region of southern China. The results can be used as reference for the evaluation of the effect on soil and water conservation in the watershed scale of soil and water conservation in the red soil region of southern China, and are expected to provide scientific basis for the layout and management of national ecological protection and construction projects.

Keywords: Flow discharge; sediment load; variation characteristics; attribution analysis; soil and water conservation; Lake Poyang Basin; upper reaches of Ganjiang River; Pingjiang River

受区域独特自然条件 (如地形起伏大、雨量多而集中、暴雨强度大、风化作用强烈等) 以及长期不合理的 开发利用影响,南方红壤区水土流失十分严重 ${ }^{[1]}$, 水土流失面积占比高达 $15.1 \%^{\left[{ }^{[2]}\right.}$. 长期以来, 为了防治水 土流失、维护生态安全, 区域内政府与民众开展了系列水土保持工作. 自 1983 年江西兴国县纳人“全国八片 水土保持重点治理区工程”开始，经过 “国家水土保持重点建设工程”、“国家农业综合开发水土保持项目”、 “全国坡耕地水土流失综合治理工程” “长治”工程、“山水林田湖草”生态保护修复工程等国家及地方水土 保持重点工程的系统治理, 区域水土流失状况得到有效控制 ${ }^{[3]}$.

随着国家、地方系列水土流失重点治理工程的持续推进, 亟需科学评估区域水土流失治理成效, 以便为 后期生态工程科学布局提供参考. 作为水土保持的最直接效应,减流减沙效应历来是水土保持效应评价关 注的重点 ${ }^{[4-8]}$. 坡面尺度水土保持减流减沙效应评价主要依托水土保持措施监测数据, 通过对比分析获 取 $^{[7,9]}$. 涉及流域或区域尺度时, 也可通过坡面尺度单项措施效应类推或累加估算结果加以评估 ${ }^{[10]}$,但该方 法需要基于不同类型水土保持措施减流减沙效应的研究结果实施, 对前期相关积累要求较高、工作量较大, 且多比较两个时间片段的监测数据, 而导致高估或低估治理成效 ${ }^{[11]}$, 再加上存在尺度效应 ${ }^{[12]}$, 结果的科学 性和准确性有待商榷.

依托长时间序列径流泥沙数据分析结果估算减流减沙效应, 为流域尺度的水土保持减流减沙效应评价 提供了较为可行的思路, 受到了相关学者的广泛关注 ${ }^{[4,13-15]}$. 具体应用时, 先通过累积距平、滑动 $t$ 检验、线 性回归、Mann-Kendall 检验、Pettitt 检验等方法进行水沙变化趋势分析与突变点识别 ${ }^{[16]}$, 再进一步通过双累 积曲线法 ${ }^{[17]}$ 、累积量斜率变化率比较法 ${ }^{[18]} 、$ SWAT 模型 ${ }^{[19]}$ 、Budyko 假设 ${ }^{[20-21]}$ 等方法区分气候变化与人类活 动对河流水沙变化的贡献,进而据此估算水土保持减流减沙效应. 该类方法在黄土高原区水土保持减流减 沙效应评价中取得了较好的效果 ${ }^{[5-6,22-23]}$. 与黄土高原区不同, 南方红壤区水库星罗棋布, 近年来水电开发迅 猛发展, 尽管通过长时间序列径流泥沙数据能够区分自然因素和人类活动对河流径流泥沙的影响, 但难以 将水土保持的减流减沙效应与其他水利工程的影响准确加以区分 ${ }^{[2-27]}$. 唯有摈除水库建设等大型水利工程 的影响,方可基于长时间序列水沙数据科学精准地开展流域水土保持减流减沙效应评价.

因此, 本文选取南方红壤区水土流失治理最为集中的鄱阳湖流域赣江上游平江流域, 以流域内中型以 上水库全部建成后的 1975-2014 年长时间序列水沙数据为基础, 开展河流水沙变化特征及归因分析, 揭示 
长期水土流失治理背景下的平江水沙变化特征, 评估流域水土保持减流减沙效应. 研究结果有望为南方红 壤区系列国家生态保护与建设工程的布局和管理提供科学依据.

\section{1 研究区与研究方法}

\section{1 研究区概况}

平江为鄱阳湖主要人湖河流——赣江上游右岸一级支流, 属山区河流, 流域面积 $2851 \mathrm{~km}^{2}$, 主河道长 $148 \mathrm{~km}$ 、比降为 $1.26 \%$. 平江流域 $\left(25^{\circ} 57^{\prime} \sim 26^{\circ} 37^{\prime} \mathrm{N}, 115^{\circ} 04^{\prime} \sim 115^{\circ} 52^{\prime} \mathrm{E}\right.$ ) 位于南方红壤区, 地带性土壤为红 壤. 受亚热带季风气候影响, 雨量充沛, 气候温暖, 多年平均降水量 $1585 \mathrm{~mm}$, 平均气温 $18.8^{\circ} \mathrm{C}^{[28]}$.

平江纵贯江西省赣州市兴国县全境, 在兴国县境内流域面积 $2274 \mathrm{~km}^{2}$, 占兴国全县国土面积的 $71 \%$. 平 江控制性水文站为翰林桥站,其观测断面以上流域面积为 $2689 \mathrm{~km}^{2}$, 其中兴国县境内流域面积占 $85 \%{ }^{[28]}$. 因此,兴国县水土流失综合治理情况基本反映了平江流域的水土保持状况.

兴国县是我国南方水土流失最严重的县市之一. 历史上水土流失面积最大时为 1975 年的 $2111.83 \mathrm{~km}^{2}$, 占全县土地总面积的 $65.7 \%$, 占山地面积的 $94.8 \%{ }^{[29]} .1970 \mathrm{~s}$ 后期开始, 当地群众自发或有组织地开展水土 流失治理, 1983 年起, 兴国县列人了 “全国八片水土保持重点治理区工程”, 开始了以小流域为单元的水土 流失综合治理, 从此拉开了南方红壤区大规模、系统性水土流失综合治理的序幕. 30 多年来,历经全国八片 水土保持重点治理区工程一期 (1983-1992 年)、二期 (1993-2002 年)、国家水土保持重点建设工程三期 $(2003-2007$ 年)、四期 $(2008-2012$ 年)、五期 (2013-2017 年) 等国家水土保持重点工程. 兴国县水 土流失治理面积不断增加, 水土流失面积逐年下降. 据江西省水利厅内部刊印的《江西水利年鉴》资料显 示, 全县水土流失综合治理面积由 1989 年的 1061.00 $\mathrm{km}^{2}$ 增加至 2011 年的 $1944.10 \mathrm{~km}^{2}$ (图 1); 治理前期兴 国县水土流失治理以营造水保林为主, 1990 年营造水 保林面积占全部水土流失治理面积的 $99.1 \%$, 至 1997 年营造水保林面积占比仍高达 $88.8 \%$,治理后期多种 水土保持措施并重, 2005 年营造水保林、经济林、种 草、封禁治理、保土耕作、修建水平梯田及其他水保措 施面积分别占 $50.9 \% 、 6.0 \% 、 3.9 \% 、 26.4 \% 、 3.1 \%$ 、 $0.2 \% 、 9.6 \%$ (表 1 ).

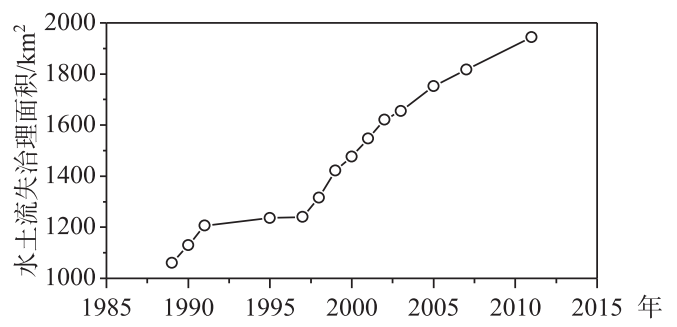

图 1 兴国县 1989-2011 年水土流失 综合治理面积变化

Fig.1 The temporal variation of soil and water conservation area in Xingguo County from 1989 to 2011

表 1 兴国县 1990、1997 和 2005 年各水土保持措施面积

Fig. 1 Areas of each soil and water conservation measures in Xingguo County in 1990, 1997 and 2005

\begin{tabular}{ccccccccc}
\hline 年份 & $\begin{array}{c}\text { 水平梯田/ } \\
\mathrm{km}^{2}\end{array}$ & $\begin{array}{c}\text { 水保林/ } \\
\mathrm{km}^{2}\end{array}$ & $\begin{array}{c}\text { 经济林/ } \\
\mathrm{km}^{2}\end{array}$ & $\begin{array}{c}\text { 种草/ } \\
\mathrm{km}^{2}\end{array}$ & $\begin{array}{c}\text { 封禁治理/ } \\
\mathrm{km}^{2}\end{array}$ & $\begin{array}{c}\text { 保土耕作/ } \\
\mathrm{km}^{2}\end{array}$ & $\begin{array}{c}\text { 其他/ } \\
\mathrm{km}^{2}\end{array}$ & $\begin{array}{c}\text { 合计/ } \\
\mathrm{km}^{2}\end{array}$ \\
\hline 1990 & - & 1119.93 & 0 & 3.00 & 0 & 0 & 7.00 & 1129.93 \\
1997 & - & 1101.50 & - & 58.40 & 0 & 0 & 81.00 & 1240.90 \\
2005 & 2.70 & 891.50 & 104.40 & 69.00 & 461.90 & 54.00 & 168.40 & 1751.90 \\
\hline
\end{tabular}

“-”表示无对应数据.

平江流域共有中型及以上水库 3 座, 依次为长冈水库、长龙水库、金盘水库, 分别于 1970 年 12 月、1960 年 3 月和 1974 年 5 月竣工运行. 鉴于水库对河流流量和输沙量具有显著的调节作用, 本文选取 1975 年以来 的数据开展分析研究.

\section{2 数据来源}

本文所用数据主要包括翰林桥站 1975-2014 年的逐日降水量 $(0.1 \mathrm{~mm})$ 、日平均流量 $\left(0.1 \mathrm{~m}^{3} / \mathrm{s}\right)$ 、日平 均含沙量 (为悬移质, $0.001 \mathrm{~kg} / \mathrm{m}^{3}$,下同) 和流域内 5 个雨量站的日降水量 (图 2 ), 数据由江西省水文局共 
享. 基于流量和含沙量数据计算得到日径流量和输沙量, 全年、汛期、非汛期降水量、径流量和输沙量则由对 应时段的日数据累积得到. 按照水文部门的划分, 平江流域的汛期为 4-9 月,其他时段为非汛期.

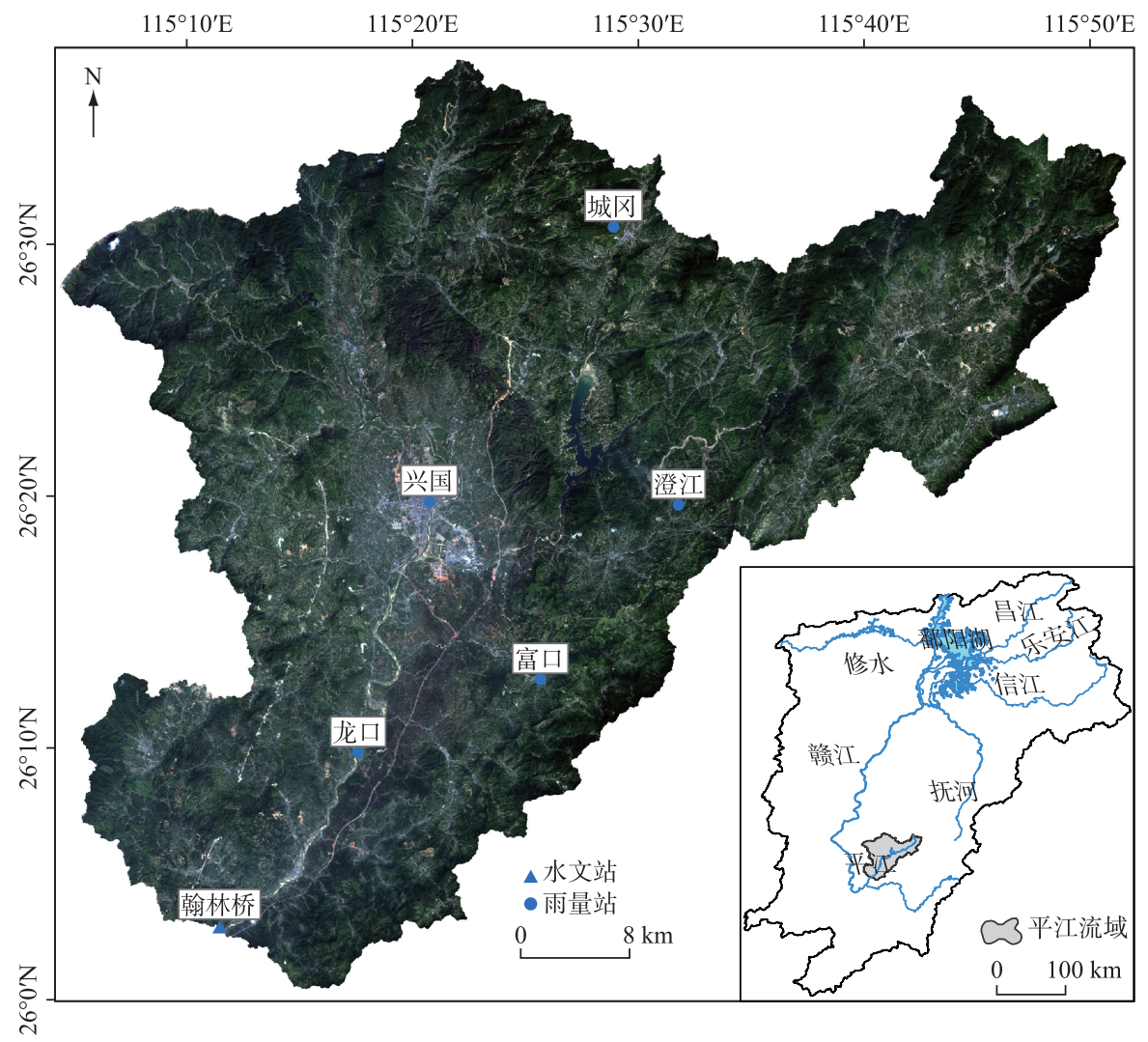

图 2 平江流域及水文站、雨量站分布

Fig. 2 Distribution of Pingjiang River Watershed, hydrological station and rain gauging stations

\section{3 研究方法}

本文先应用预置白 M-K 检验法 (Pre-whitening Mann-Kendall $)^{[30]}$ 和 Theil-Sen 趋势度估计法 ${ }^{[31]}$ 分析 1975-2014 年降水量、径流量、输沙量数据序列的变化趋势并估算变化率, 再针对存在显著变化趋势的数据 序列使用 Pettitt 检验法 ${ }^{[32]}$ 检测突变点, 在此基础上, 通过累积量斜率变化率比较法 ${ }^{[18]}$ 开展影响因素定量 分析.

累积量斜率变化率比较法的原理如下 ${ }^{[18,33]}$ : 假设累积输沙量一年份线性关系式和累积降水量一年份线 性关系式的斜率在突变点前后分别为 $S_{\mathrm{Sb}} 、 S_{\mathrm{Sa}}$ (单位: $\left.10^{4} \mathrm{t} / \mathrm{a}\right)$ 和 $S_{\mathrm{Pb}} 、 S_{\mathrm{Pa}}$ (单位: $\mathrm{mm} / \mathrm{a}$ ), 则累积输沙量斜率变 化率 $R_{\mathrm{SS}}$ 和累积降水量斜率变化率 $R_{\mathrm{SP}}$ 分别为:

$$
\begin{aligned}
& R_{\mathrm{SS}}=\left(\frac{S_{\mathrm{Sa}}}{S_{\mathrm{Sb}}}-1\right) \times 100 \% \\
& R_{\mathrm{SP}}=\left(\frac{S_{\mathrm{Pa}}}{S_{\mathrm{Pb}}}-1\right) \times 100 \%
\end{aligned}
$$

降水量变化对输沙量变化的贡献率 $C_{\mathrm{P}}$ 为:

$$
C_{\mathrm{P}}=\frac{R_{\mathrm{SP}}}{R_{\mathrm{SS}}} \times 100 \%
$$

气温变化通过影响蒸发量变化引起径流量变化, 进而导致输沙量变化, 如果用 $C_{\mathrm{ET}}$ 表示流域内气温变化 
对输沙量变化的贡献率, 则人类活动对输沙量变化的贡献率 $C_{\mathrm{H}}$ 为:

前人相关研究 ${ }^{[33-34]}$ 一般认为 $C_{\mathrm{ET}}$ 近似为 0 , 则:

$$
C_{\mathrm{H}}=1-C_{\mathrm{P}}-C_{\mathrm{ET}}
$$

$$
C_{\mathrm{H}}=1-C_{\mathrm{P}}
$$

鉴于流域平均降水量需基于 6 个站点的降水量求取, 本文在正式开展分析前先采用双累积曲线法 ${ }^{[17,35]}$ 对降水数据进行一致性检验. 1975-2014 年平江流域 6 个站点的降水量双累积曲线分析结果如图 3 所示, 各自的双累积曲线图均呈现显著的线性关系 $\left(R^{2}>0.99, P<0.01\right)$, 表明研究时段内 6 个站点的降水量数据一 致性均较好, 能够满足后期分析需要. 后文所用的降水量为基于以上 6 个站点降水数据采用泰森多边形法 求得的流域平均降水量.
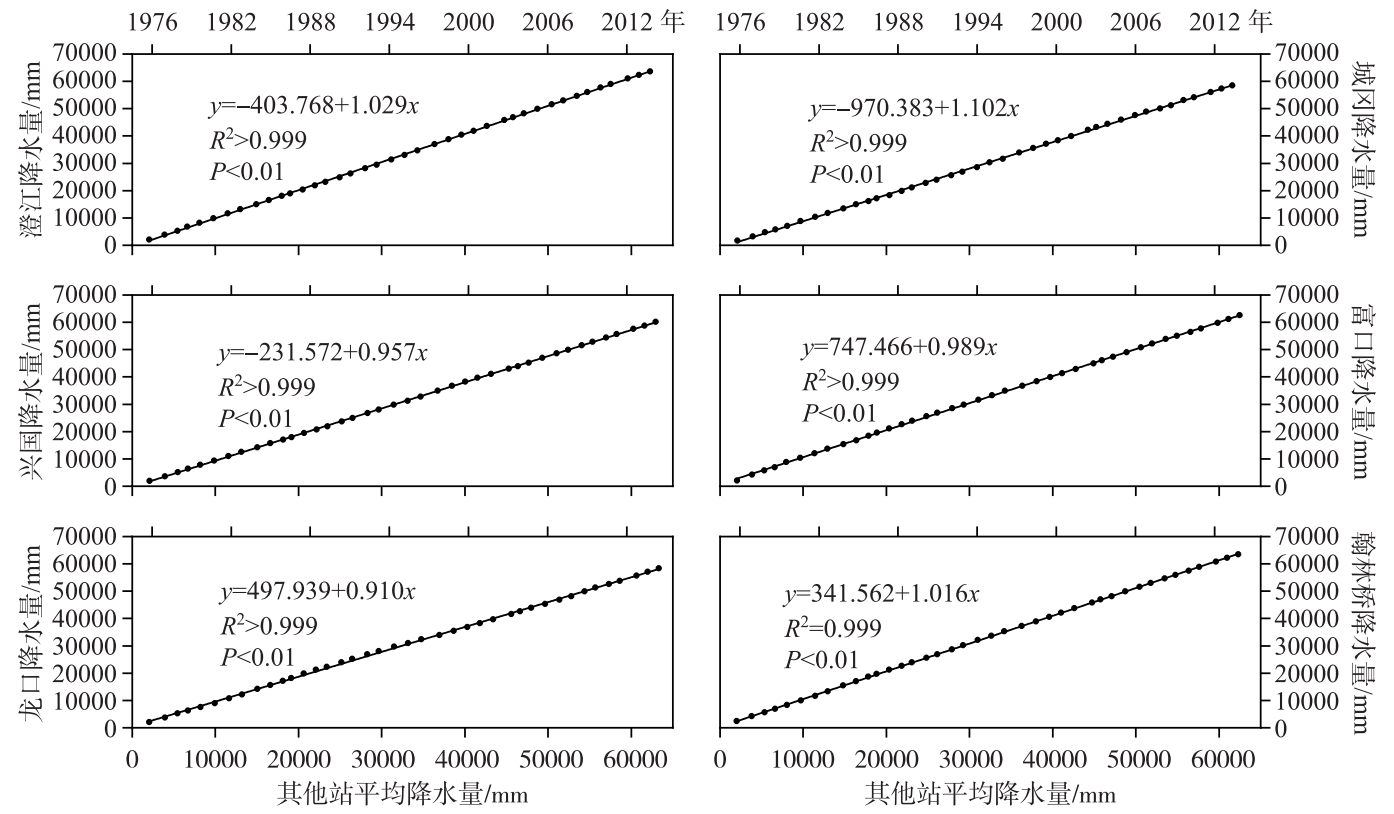

图 3 平江流域雨量站降水一致性检验

Fig.3 Consistency test of precipitation for different rain gauging stations in Pingjiang River Watershed

除累积量斜率变化率比较法在 Excel 2013 中计算得到, 其他数据分析主要通过 R 3.4.1 实现, 制图主要 基于 Origin 9.0 完成.

\section{2 结果与分析}

\section{1 年际变化趋势与突变点}

基于预置白 M-K 检验法和 Theil-Sen 趋势度估计法分析了 1975- 2014 年平江流域降水量、径流量和输 沙量变化趋势, 结果如表 2 所示. 不难看出: 研究时段无论是全年还是汛期、非汛期, 平江输沙量均存在极显 著减少趋势 $(Z<-2.58)$, 其年均减少率分别为 $2.38 \times 10^{4} 、 1.75 \times 10^{4}$ 和 $0.44 \times 10^{4} \mathrm{t} / \mathrm{a}$; 同时, 平江年均含沙量和 最大含沙量也均存在极显著减少趋势 $(Z<-2.58)$, 其年均减少率分别为 0.004 和 $0.045 \mathrm{~kg} / \mathrm{m}^{3}$. 此外, 平江流 域各个时期的降水量和径流量以及洪峰流量、年均流量也存在减少趋势, 但均不显著 $(|Z|<1.65)$; 而最枯流 量和年最小含沙量均呈现一定的增大趋势,也均不显著 $(|Z|<1.65)$.

降水量、径流量虽然有降低趋势, 但并不显著, 因此, 本文仅针对变化趋势显著的输沙量和含沙量数据 序列, 进一步采用 Pettitt 检验法开展突变点检验, 结果如图 4 和图 5 所示. 由图 4 可知, 1975-2014 年平江 的年输沙量、汛期输沙量和非汛期输沙量均存在极显著的突变点 $(P<0.01)$, 分别为 $1998 、 1985$ 和 1998 年. 
表 2 平江流域降水、径流和输沙量预置白 M-K 趋势分析和 Theil-Sen 趋势度估计结果 *

Tab.2 Pre-whitening Mann-Kendall trend analysis and Theil-Sen trend estimate of precipitation, flow and sediment transport in Pingjiang River Watershed

\begin{tabular}{|c|c|c|c|c|c|c|}
\hline & \multirow{2}{*}{ 量量 } & \multirow{2}{*}{$Z$ 统计量 } & \multirow{2}{*}{$P$} & \multirow{2}{*}{$\begin{array}{c}\text { Theil-Sen's slope } \\
\text { 拟合值 }\end{array}$} & \multicolumn{2}{|c|}{ Theil-Sen's slope 拟合值 95\% 置信区间 } \\
\hline & & & & & 下限 & 上限 \\
\hline \multirow[t]{3}{*}{ 降水量 } & 全年 & -0.83 & 0.41 & -3.45 & -10.26 & -137.90 \\
\hline & 汛期 & -0.48 & 0.63 & -0.99 & -7.21 & -39.68 \\
\hline & 非汛期 & -1.29 & 0.20 & -2.61 & -6.02 & -104.45 \\
\hline \multirow[t]{3}{*}{ 流量 } & 年均 & -0.59 & 0.55 & -0.17 & -0.89 & -6.73 \\
\hline & 最大 & -0.44 & 0.66 & -3.74 & -17.60 & -149.80 \\
\hline & 最小 & 1.40 & 0.16 & 0.09 & -0.04 & 3.58 \\
\hline \multirow[t]{3}{*}{ 径流量 } & 全年 & -0.59 & 0.55 & -0.05 & -0.28 & -2.12 \\
\hline & 汛期 & -0.48 & 0.63 & -0.04 & -0.18 & -1.68 \\
\hline & 非汛期 & -0.90 & 0.37 & -0.03 & -0.10 & -1.16 \\
\hline \multirow[t]{3}{*}{ 含沙量 } & 平均 & -6.39 & $<0.01$ & $<0.01$ & $<0.01$ & -0.15 \\
\hline & 最大 & -5.56 & $<0.01$ & -0.09 & -0.11 & -3.48 \\
\hline & 最小 & 0.10 & 0.92 & $<0.01$ & $<0.01$ & $<0.01$ \\
\hline \multirow[t]{3}{*}{ 输沙量 } & 全年 & -5.54 & $<0.01$ & -2.38 & -3.11 & -95.23 \\
\hline & 汛期 & -4.31 & $<0.01$ & -1.75 & -2.65 & -70.14 \\
\hline & 非汛期 & -3.00 & $<0.01$ & -0.44 & -0.77 & -17.68 \\
\hline
\end{tabular}

$* Z$ 为 M-K 检验法的统计量, $P<0.05$ 表明数据序列存在显著趋势.

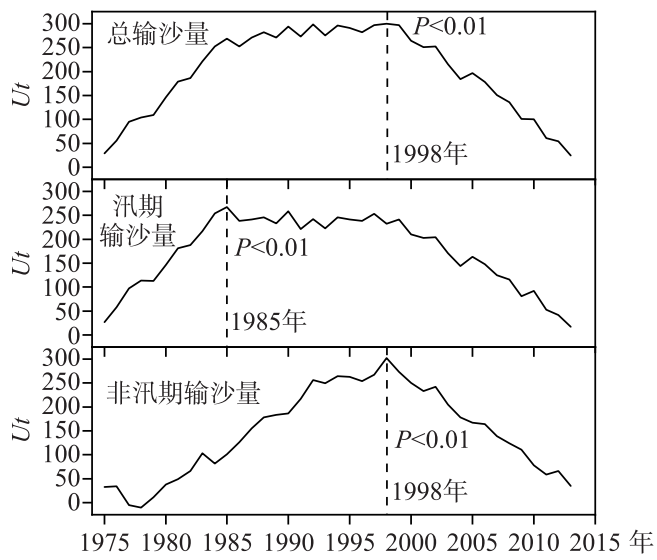

图 4 1975-2014 年平江输

沙量 Pettitt 法突变点检验 $(U t$ 统计量为 Pettitt 检验法的统计量, $U t$ 最大的年份即为可能的突 变点, $P<0.05$ 表明检测出的突变点 在统计意义上是显著的. 下同)

Fig.4 Pettitt test for change-point detection of sediment load for Pingjiang River from 1975 to 2014 ( $U t$ is the statistic of Pettitt test, and the probable change-point is located at the year where $U t$ is maximized, and $P<0.05$ indicates that it's significant for the detected change-point. The same below)
此外, 平均含沙量和最大含沙量也存在极显著的突 变点, 分别为 1994 和 1996 年. 与输沙量突变点相 比, 平均含沙量和最大含沙量的突变年份均早于全 年输沙量,但晚于汛期输沙量.

\section{2 各阶段变化特征}

基于全年输沙量、汛期输沙量和非汛期输沙量 的突变年份, 结合流域水土保持工程实施情况, 可 以据此将整个研究期划分为 3 个时间段: 19751984 年、1985-1997 年、1998-2014 年, 分别对应 治理前、重点治理期和治理后期.

表 3 为平江各时间段全年、汛期和非汛期的降 水量、径流量与输沙量以及汛期占比情况. 总体而 言, 整个研究时段流域降水量变化相对较小, 与治 理前相比, 重点治理期与治理后期的年降水量仅分 别减少了 $5.8 \%$ 和 $6.0 \%$, 反映出影响流域产流产沙 的外部因素相对稳定. 而无论是全年、还是汛期和 非汛期的输沙量, 治理后期均显著少于治理前, 减 少率分别高达 $62.6 \%$ 、63.0\% 和 $60.7 \%$; 治理后期全 年、汛期和非汛期的径流量也有所减少, 减少率分 别为 $10.4 \% 、 12.8 \%$ 和 $4.4 \%$. 重点治理期, 全年径流 量和输沙量也分别较治理前减少了 $12.1 \%$ 和 $39.5 \%$, 但主要发生在汛期, 汛期径流量和输沙量分别减少 了 $16.8 \%$ 和 $47.9 \%$; 至于非汛期, 重点治理期径流量 
基本不变,而输沙量则较治理前增加了 $4.1 \%$.

\section{3 输沙量变化归因}

影响河流输沙的因素主要包含两个方面,一是自然 因素,二是人类活动. 自然因素主要包含地形、土壤等下 垫面条件和气候条件,通过改变坡面产流产沙过程影响 河流输沙状况，一般认为自然状态下垫面在一定时间尺 度上是不发生改变的,因此自然因素主要考虑的是气候 因素如降水、蒸发的影响,而前人相关研究 ${ }^{[33-34]}$ 认为蒸 发对河流输沙的影响可以忽略不计. 鉴于此, 本研究采 用了累积量斜率变化率比较法对人类活动和降水变化 对平江输沙量变化的影响进行分析 ${ }^{[33-34]}$.

针对各阶段全年、汛期、非汛期平江输沙量和流域 降水量, 分别绘制对应时段的累积输沙量一年份、累积 降水量一年份关系曲线 (图 6), 得到各阶段累积输沙 量一年份、对应阶段累积降水量一年份的线性关系. 由

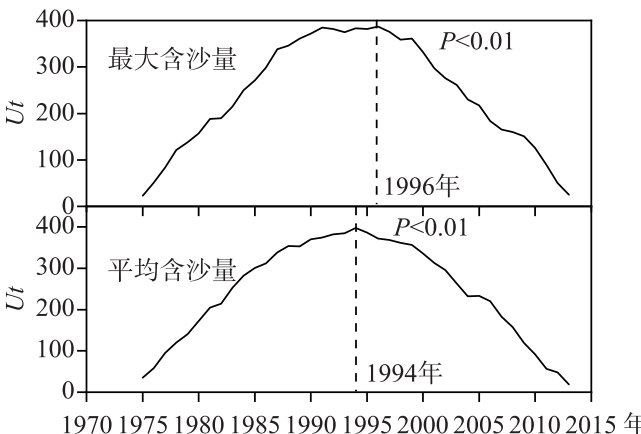

图 5 1975-2014 年

平江含沙量 Pettitt 法突变点检验

Fig.5 Pettitt test for change-point detection of sediment concentration for Pingiang

River from 1975 to 2014 图 6 可见,平江各时段的全年、汛期和非汛期的累积输 沙量、流域累积降水量与对应年份均存在显著的线性关系 $\left(P<0.01, R^{2}>0.99\right)$. 因此,可以基于累积斜率变化 率比较法分析人类活动和降水变化对平江输沙量变化的影响.

表 3 平江流域不同治理阶段全年、汛期和非汛期降水量、径流量与输沙量

Tab.3 Precipitation, flow discharge and sediment load of whole year, flood period, non-flood period in Pingjiang River Watershed for different control periods

\begin{tabular}{|c|c|c|c|c|c|c|c|c|c|c|c|c|}
\hline \multirow{2}{*}{ 阶段 } & \multicolumn{3}{|c|}{ 降水量/ (mm/a) } & \multicolumn{3}{|c|}{ 径流量 $/\left(\times 10^{8} \mathrm{~m}^{3} / \mathrm{a}\right)$} & \multicolumn{3}{|c|}{ 输沙量 $/\left(\times 10^{4} \mathrm{t} / \mathrm{a}\right)$} & \multicolumn{3}{|c|}{ 汛期比例 } \\
\hline & 全年 & 汛期 & 非汛期 & 全年 & 汛期 & 非汛期 & 全年 & 汛期 & 非汛期 & 降雨量 & 径流量 & 输沙量 \\
\hline 治理前 & 1637.3 & 1124.5 & 512.8 & 25.99 & 18.66 & 7.33 & 124.36 & 104.28 & 20.08 & $68.7 \%$ & $71.8 \%$ & $83.9 \%$ \\
\hline 重点治理期 & 1542.9 & 985.5 & 557.4 & 22.85 & 15.52 & 7.32 & 75.20 & 54.29 & 20.91 & $63.9 \%$ & $67.9 \%$ & $72.2 \%$ \\
\hline 治理后期 & 1539.6 & 1055.4 & 484.2 & 23.28 & 16.28 & 7.00 & 46.49 & 38.61 & 7.88 & $68.6 \%$ & $69.9 \%$ & $83.0 \%$ \\
\hline
\end{tabular}

(a) 全年

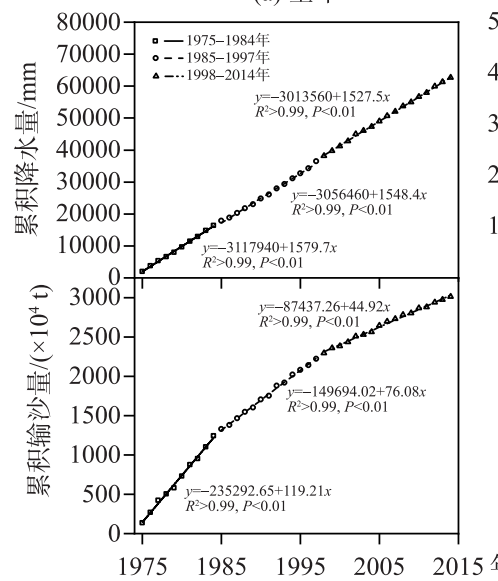

(b) 汛期

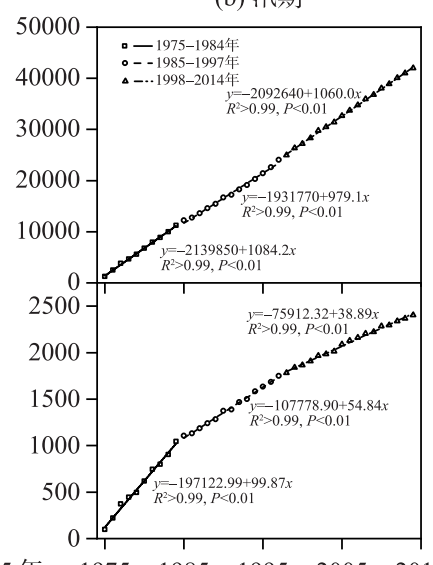

(c) 非汛期

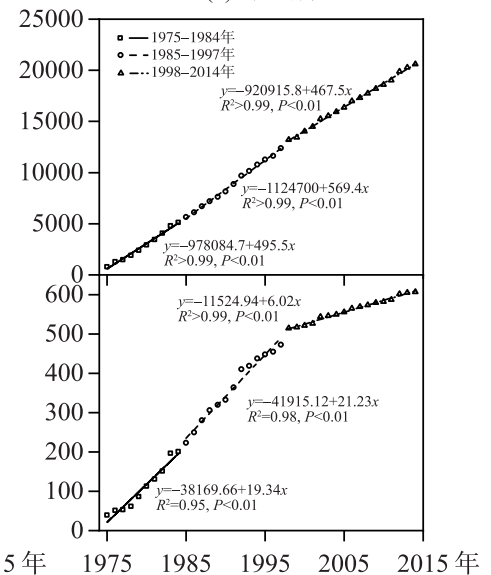

图 6 平江流域全年 (a)、汛期 (b) 和非汛期 (c) 累积输沙量一年份与累积降水量一年份的关系曲线

Fig.6 Relationships between accumulative sediment load and year and between accumulative precipitation and year of whole year (a), flood period (b) and non-flood period (c) in Pingjiang River Watershed 
采用累积斜率变化率比较法,得到全年、汛期、非汛期的人类活动和降水变化以及对相应时段输沙量变 化的贡献率 (表 4). 从平江全年输沙量来看, 无论是重点治理期还是治理后期, 人类活动均是输沙量减少的 主导因子, 其贡献率分别高达 94.5\% 和 94.7\%, 而降水量变化的贡献率分别仅占 5.5\% 和 5.3\%. 治理后期汛 期和非汛期人类活动和降水变化对平江汛期输沙量变化的影响与全年的类似, 也是均由人类活动绝对主 导, 降水量变化对平江汛期和非汛期输沙量减少的贡献分别仅为 3.7\% 和 $8.2 \%$. 重点治理期, 人类活动和降 水变化对平江汛期和非汛期输沙量变化的影响与其他阶段有所不同: 汛期降水量变化对其输沙量减少的贡 献率有所增加, 达到了 $21.5 \%$; 而非汛期输沙量有所增加, 主要与该阶段非汛期降水量增加有关, 人类活动的 贡献为 $-52.5 \%$, 意味着该时期人类活动对非汛期输沙量增加的贡献为负, 反映出即使该阶段非汛期输沙量 有所增加, 人类活动仍然在一定程度上减少了平江输沙量.

表 4 人类活动和降水变化对平江输沙量的影响

Tab.4 Impact of human activity and precipitation change on sediment load of Pingjiang River

\begin{tabular}{|c|c|c|c|c|c|c|c|}
\hline \multirow{2}{*}{ 时段 } & \multirow{2}{*}{ 治理阶段 } & \multicolumn{2}{|c|}{ 累积量与年份线性斜率 } & \multicolumn{2}{|c|}{ 累积量斜率减小率 } & \multicolumn{2}{|c|}{ 对输沙量变化的贡献率 } \\
\hline & & 降水量/( mm/a) & 输沙量 $/\left(\times 10^{4} \mathrm{t} / \mathrm{a}\right)$ & 降水量 & 输沙量 & 降水 & 人类活动 \\
\hline \multirow[t]{3}{*}{ 全年 } & 治理前 & 1579.7 & 119.21 & - & - & - & - \\
\hline & 重点治理期 & 1548.4 & 76.08 & $2.0 \%$ & $36.2 \%$ & $5.5 \%$ & $94.5 \%$ \\
\hline & 治理后期 & 1527.5 & 44.92 & $3.3 \%$ & $62.3 \%$ & $5.3 \%$ & $94.7 \%$ \\
\hline \multirow[t]{3}{*}{ 汛期 } & 治理前 & 1084.2 & 99.87 & - & - & - & - \\
\hline & 重点治理期 & 979.1 & 54.84 & $9.7 \%$ & $45.1 \%$ & $21.5 \%$ & $78.5 \%$ \\
\hline & 治理后期 & 1060.0 & 38.89 & $2.2 \%$ & $61.1 \%$ & $3.7 \%$ & $96.3 \%$ \\
\hline \multirow[t]{3}{*}{ 非汛期 } & 治理前 & 495.5 & 19.34 & - & - & - & - \\
\hline & 重点治理期 & 569.4 & 21.23 & $-14.9 \%$ & $-9.8 \%$ & $152.5 \%$ & $-52.5 \%$ \\
\hline & 治理后期 & 467.5 & 6.02 & $5.7 \%$ & $68.9 \%$ & $8.2 \%$ & $91.8 \%$ \\
\hline
\end{tabular}

“-”表示无对应数据.

\section{3 讨论}

\section{1 水沙变化影响因素分析}

降水是径流的直接来源, 也是侵蚀产沙的重要驱动力, 而径流则为河流输沙的主要载体. 理想状况下, 流域下垫面变化不大时, 其降水状况的显著变化必然改变流域产流、产沙状况,进而使得河流水沙状况发生 相应的改变. 一般而言, 降水增加将导致产流产沙增多, 河流径流量与输沙量增大, 且该影响在对降水更为 敏感的干早、半干旱地区表现尤为明显 ${ }^{[36]}$. 但实际上,降水变化还会在一定程度上影响流域植被状况, 而流 域植被状况的改变也会通过影响产流、产沙过程导致河流水沙状况发生变化 ${ }^{[37]}$, 因此, 湿润区、半湿润区流 域水沙过程对降水变化的响应较干旱半干旱区更为复杂 ${ }^{[36]}$.

研究时段内, 平江流域径流量与降水量呈现同步变化趋势, 且均有所减少, 但趋势均不显著, 反映了雨 水丰沛、植被状况相对较好的南方红壤区内,降水变化对径流变化发挥主导作用. 尽管研究时段内平江流域 降水量和径流量未发生显著变化, 但平江径流含沙量和输沙量均存在显著减少趋势, 竷江流域的相关研 究 ${ }^{[24,27,38]}$ 也发现了相似的规律, 反映出降水及其主导的径流变化并非研究时段平江流域输沙量减少的主要 驱动因素, 流域产沙减少导致河流来沙剧减与河流输沙能力减弱共同作用引起的径流含沙量显著减少可能 才是平江输沙量显著减少的主要原因.

当前, 影响河流水沙状况的高强度人类活动主要包括生态保护 (如退耕还林还草、坡改梯、封山育林等 水土保持措施)、水利工程 (如修建水库、灌溉引水等)、基础设施建设 (如城市改扩建、修路架桥) 等 ${ }^{[19,23]}$. 一 方面, 大范围的生态保护工程与高强度的基础设施建设显著影响流域下垫面状况, 改变流域产流产沙过程, 影响河流水沙来源; 另一方面, 蓬勃发展的水利工程通过重塑河流形态和水文状况, 改变河流携沙能力, 影 响河流水沙输送. 平江流域所在的兴国、赣县, 经济相对欠发达,城镇化水平整体相对较低. 基于历史土地利 
用数据分析发现, 1980- 2013 年,平江流域包含城镇、道路、厂矿在内的建设用地占比仅从 $0.7 \%$ 增至 $0.9 \%$, 建设用地占比低, 因此, 基建工程对平江输沙量的影响非常有限, 且有限的影响也应以增加河流泥沙输送为 主. 自 1974 年 5 月以来,平江流域没有新建中型以上水库 ${ }^{[28]}$, 因此, 研究期内水利工程建设对平江输沙量的 影响也无显著变化. 径流进人已运行水库, 在未改变水库运行调度方案的情况下,年际尺度上进、出水库流 量相当,已运行水库对多年平均径流量的影响基本可以忽略不计, 但受人库径流流速降低、携沙能力减弱影 响,泥沙发生沉积, 导致泥沙输出量减少. 一般而言,在河流来沙稳定的情况下,已建水库对河流输沙量拦截 效果基本不变; 但河流来沙减少时, 水库对河流输沙量的拦截效果也会相应减弱; 而河流来沙增加时则反之. 不难看出,经水库拦截后的输沙量变化,在一定程度上也能反映河流来沙量的变化. 据此推断, 1975-2014 年间,平江来沙总体上呈现先增加、至 1980s 达到峰值而后减少的状况,因而研究期内水库拦沙效应也呈现 先增加、至 1980s 达到峰值而后减少的规律. 因此, 本研究期内, 流域已建水库对平江输沙的影响以拦沙量减 少为主. 而自 1983 年兴国县列人了 “全国八片水土保持重点治理区工程” 起, 平江流域大规模的水土保持工 作至今已持续了 30 多年. 鉴于此, 研究时段内平江含沙量及输沙量显著减少, 最可能与流域内长期持续开 展的以水土保持为主的大规模生态保护工程有关.

\section{2 对南方红壤区流域水土保持减流减沙效应评价的启示}

分析水土保持对区域生态环境的影响, 科学合理评价水土保持工程的实施成效, 有助于查明实施过程 中存在的问题, 为后续工程实施与科学布局提供参考依据. 作为水土保持的最直接成效, 减流减沙效应历来 是水土保持效应评价关注的重点. 与坡面尺度效应评价主要基于措施对照不同,流域尺度的水土保持减流 减沙效应评价主要依托长时间序列径流泥沙数据分析开展 ${ }^{[12,39]}$. 南方红壤区大中型水库星罗棋布, 而王延 贵等 ${ }^{[40]}$ 研究发现长江干支流水沙参数与流域水库库容参数之间有重要关系, 主要水文站年输沙量随流域累 积库容增加而逐渐减少, 来沙系数和输沙模数随流域水库调控系数呈指数关系衰减, 水库蓄水拦沙是水沙 态势变异的主要因素; 杨维鸽等 ${ }^{[41]}$ 认为长江干流各水文站输沙量减少的主要原因是水库拦沙和水土保持措 施控蚀减沙; 赣江流域的相关研究也认为水利工程建设和水土保持等人类活动对流域输沙量变化影响极其 显著 ${ }^{[24-25,27]}$. 可见, 南方红壤区基于长时间序列河流水沙观测数据评价流域水土保持减流减沙效应时,必须 剔除大型水利工程 (尤其是大中型水库) 建设对河流水沙的影响, 否则必将高估流域水土保持减流减沙 效应.

\section{3 长期水土保持对平江流域水沙状况的影响}

自 1983 年列入 “全国八片水土保持重点治理区工程” 起, 兴国县经过系列国家水土保持重点工程的持 续治理, 截至 2011 年, 共完成水土流失综合治理 $1944.1 \mathrm{~km}^{2}$, 水土流失面积降至 $568.84 \mathrm{~km}^{2}$. 治理后期, 平江 全年、汛期和非汛期输沙量均显著少于治理前, 减少率分别高达 62.6\%、63.0\% 和 $60.7 \%$; 治理后期全年、汛期 和非汛期的径流量也有所减少, 减少率分别为 $10.4 \%$ 、 $12.8 \%$ 和 $4.4 \%$, 但均不显著. 人类活动对治理后期全 年、汛期、非汛期输沙量减少的贡献率分别高达 94.7\%、96.3\%、91.8\%, 3.1 节分析中也排除了基础设施建设、 水利工程等的影响, 可以认为导致平江流域输沙量减少的人类活动就是长期水土保持. 由此可知, 流域长期 水土保持导致平江输沙量显著减少, 但对径流量的影响不显著. 鉴于平江流域为南方红壤区水土保持工程 最为集中、持续时间最长的典型流域, 可以理解为南方红壤区水土保持具有显著减沙效应,但减流效应不显 著. 刘二佳等 ${ }^{[15]}$ 、綦俊谕等 ${ }^{[12]}$ 、赵跃中等 ${ }^{[14]}$ 在黄土高原区的研究发现, 水土保持具有显著的减流减沙效益, 郑江坤等 ${ }^{[13]}$ 在川北紫色土小流域研究中也发现, 大规模的植被建设在减少土壤侵蚀的同时也减少了产流 量, 而位于南方红壤区的平江流域的研究结果却不太一致,长期水土保持仅发挥了显著的减沙效益, 对产流 无显著影响. 涂安国等 ${ }^{[4]}$ 在赣江流域的相关研究也发现类似的规律, 可能是因为南方红壤区雨水较为充沛, 且区域水土保持以营建水保林和开展封禁治理等植被恢复措施为主, 而通过植被的林冠截留、枯枝落叶层 拦蓄等作用,增加土壤人渗,减少地表径流,有助于削减洪峰流量, 增加常水流量 ${ }^{[4,13]}$. 此外, 黄土高原区 ${ }^{[12]}$ 与紫色土区 ${ }^{[13]}$ 的研究均发现, 水土保持对产沙的影响远大于径流的影响, 也在一定程度上印证了本研究的 相关结果. 重点治理期, 年输沙量较治理前减少了 $39.5 \%$, 远小于治理后期输沙量的减小比例, 可能是由于 水土保持效益随时间的变化是非线性的, 总体上表现为先缓慢增大、后急剧增大的规律 ${ }^{[8]}$. 基于输沙量变化 率及水土保持为主的人类活动贡献率, 可以简单推算出长期水土保持导致治理后期平江全年、汛期、非汛期 
输沙量分别减少 $59.3 \%$ 、60.7\% 和 $55.7 \%$, 也即平江流域水土保持在全年、汛期、非汛期分别发挥了 $59.3 \%$ 、 $60.7 \%$ 和 $55.7 \%$ 的减沙效应.

\section{4 结论}

1) 1975-2014 年平江年输沙量、汛期输沙量和非汛期输沙量均存在显著减少趋势, 年均减少率分别为 $2.38 \times 10^{4} 、 1.75 \times 10^{4}$ 和 $0.44 \times 10^{4} \mathrm{t} / \mathrm{a}$, 汛期输沙量在流域开始实施系统水土流失治理时即发生突变, 而年输沙 量和非汛期输沙量在系列国家水土保持重点工程实施一段时间后方开始突变.

2) 流域长期水土保持显著减少平江输沙, 但对径流无显著影响. 重点治理期与治理后期, 平江年输沙量 分别较治理前减少了 $39.5 \%$ 和 $76.5 \%$, 且以汛期减少为主 ( $84.3 \%$ 以上).

3 ) 平江输沙量减少主要受以水土保持为代表的长期生态保护工程影响, 重点治理期、治理后期生态保 护工程对输沙量减少的贡献均在 $94.0 \%$ 以上, 且生态保护工程对汛期输沙量减少的贡献较非汛期更为突出; 以水土保持为主的长期生态保护工程导致平江全年、汛期、非汛期输沙量分别减少 59.3\%、60.7\% 和 $55.7 \%$.

4) 长时间序列水沙数据分析有助于科学评价流域尺度水土保持减流减沙效应,但在水库星罗棋布, 水 电开发迅猛发展的南方红壤区应用时,需剔除大型水利工程(尤其是大中型水库)建设影响.

致谢: 江西省水文局共享了翰林桥站日降雨量、流量、含沙量数据和平江流域雨量站日降雨量数据, 特此表 示感谢.

\section{5 参考文献}

[ 1 ] Liang Y, Zhang B, Pan XZ et al. Current status and comprehensive control strategies of soil erosion for hilly region in the Southern China. Science of Soil and Water Conservation, 2008, 6(1) : 22-27. DOI: 10.16843/j.sswc.2008.01.005. [梁 音, 张斌, 潘贤章等. 南方红壤丘陵区水土流失现状与综合治理对策. 中国水土保持科学, 2008, 6(1): 22-27.]

[ 2 ] MWR, CAS, CAE eds. Soil erosion control and ecological security in China: Southern red soil region volume. Beijing: Science Press, 2010: 1-275. [水利部, 中国科学院, 中国工程院. 中国水土流失防治与生态安全: 南方红壤区卷. 北京: 科学出版社, 2010: 1-275.]

[ 3 ] He CG, Liu MF, Zhang LC et al. The process and effect of soil erosion control in Jiangxi Province. Soil and Water Conservation in China, 2017, (8):10-14. [何长高, 刘茂福, 张利超等. 江西省水土流失治理历程及成效. 中国水土保 持, 2017, (8): 10-14.]

[ 4 ] Tu AG, Yang J, Li Y et al. Effects of runoff and sediment reductions by soil and water conservation measures in Ganjiang watershed. Bulletin of Soil and Water Conservation, 2013, 33(5): 148-151. [涂安国, 杨洁, 李英等. 赣江流域水土保 持生态建设减水减沙效益评价. 水土保持通报, 2013, 33(5): 148-151.]

[ 5 ] Liu XY, Yang ST, Wang FG et al. Analysis on sediment yield reduced by current terrace and shrubs-herbs-arbor vegetation in the Loess Plateau. Journal of Hydraulic Engineering, 2014, 45(11): 1293-1300. [刘晓燕, 杨胜天, 王富贵等. 黄土 高原现状梯田和林草植被的减沙作用分析. 水利学报, 2014, 45(11): 1293-1300.]

[6] Liu XY, Wang FG, Yang ST et al. Sediment reduction effect of level terrace in the hilly-gully region in the Loess Plateau. Journal of Hydraulic Engineering, 2014, 45(7): 793-800. [刘晓燕, 王富贵, 杨胜天等. 黄土丘陵沟壑区水平梯田 减沙作用研究. 水利学报, 2014, 45(7): 793-800.]

[ 7 ] Yuan XP, Lei TW. Soil and water conservation measures and their benefits in runoff and sediment reductions. Transactions of the Chinese Society of Agricultural Engineering, 2004, 20(2): 296-300. [袁希平, 雷廷武. 水土保持措施及其减水 减沙效益分析. 农业工程学报, 2004, 20(2): 296-300.]

[ 8 ] Xu JX, Sun J. Threshold phenomenon of sediment reduction beneficials from soil-water conservation measures in the Wudinghe River. Advances in Water Science, 2006, 17(5):610-615. [许昫心, 孙季. 无定河水土保持措施减沙效益的临 界现象及其意义. 水科学进展, 2006, 17(5): 610-615.]

[ 9 ] General Administration of Quality Supervision, Inspection and Quarantine of the People's Republic of China, Standardization Administration of the People's Republic of China eds. Comprehensive control of soil and water conservation-Method of benefit calculation. GB/T 15774-2008. Beijing: Standards Press of China, 2009. [中华人民共和国国家质量监督检验 检疫总局, 中国国家标准化管理委员会. 水土保持综合治理 效益计算方法 GB/T 15774-2008. 北京: 中国标准出 
版社, 2009.]

[10] Wang ZN, Wang XG, Shi YH et al. Effects of soil and water conservation of the conversion of farmland to forest in Zigui County of the Three Gorges Reservoir Region. Science of Soil and Water Conservation, 2007, 5(1) : 68-72. DOI: 10. 16843/j.sswc.2007.01.014. [王珠娜, 王晓光, 史玉虎等. 三峡库区柇归县退耕还林工程水土保持效益研究. 中国 水土保持科学, $2007, \mathbf{5}(1): 68-72$.]

[11] Shao QQ, Fan JW, Liu JY et al. Assessment on the effects of the first-stage ecological conservation and restoration project in Sanjiangyuan region. Acta Geographica Sinica, 2016, 71(1) : 3-20. DOI: 10.11821/dlxb201601001. [邵全琴, 㚞江 文, 刘纪远等. 三江源生态保护和建设一期工程生态成效评估. 地理学报, 2016, 71(1) : 3-20.]

[12] Qi JY, Cai QG, Cai L et al. Scale effect of runoff and sediment reduction effects of soil and water conservation measures in Chabagou, Dalihe and Wudinghe Basins. Progress in Geography, 2011, 30(1): 95-102. [綦俊谕, 蔡强国, 蔡乐等. 岔 巴沟、大理河与无定河水土保持减水减沙作用的尺度效应. 地理科学进展, 2011, 30(1) : 95-102.]

[13] Zheng JK, Li JY, Qin W et al. Effects of vegetation construction on soil and water conservation in small watershed of purplish soil region, northern Sichuan. Transactions of the Chinese Society of Agricultural Engineering, 2017, 33(2): 141147. [郑江坤, 李静苑, 秦伟等. 川北紫色土小流域植被建设的水土保持效应. 农业工程学报, 2017, 33(2)： 141-147.]

[14] Zhao YZ, Mu XM, Yan BW et al. Influence of vegetation restoration on runoff and sediment of Yanhe Basin. Journal of Sediment Research, 2014, (4) : 67-73. [赵跃中, 穆兴民, 严宝文等. 延河流域植被恢复对径流泥沙的影响. 泥沙研 究, 2014, (4): 67-73.]

[15] Liu EJ, Zhang XP, Xie ML et al. Hydrologic responses to vegetation restoration and their driving forces in a catchment in the Loess hilly-gully area: A case study in the upper Beiluo River. Acta Ecologica Sinica, 2015, 35(3) : 622-629. DOI: 10.5846/stxb201304100658. [刘二佳, 张晓萍, 谢名礼等. 生态恢复对流域水沙演变趋势的影响一以北洛河上 游为例. 生态学报, 2015, 35(3): 622-629.]

[16] Zhang YH, Song XF. Techniques of abrupt change detection and trends analysis in hydroclimatic time-series: Advances and evaluation. Arid Land Geography, 2015, 38(4): 652-665. [张应华, 宋献方. 水文气象序列趋势分析与变异诊断 的方法及其对比. 干旱区地理, 2015, 38(4): 652-665.]

[17] Mu XM, Zhang XQ, Gao P et al. Theory of double mass curves and its applications in hydrology and meteorology. Hydrolo$g y, 2010,30(4): 47-51$. [穆兴民, 张秀勤, 高鹏等. 双累积曲线方法理论及在水文气象领域应用中应注意的问 题. 水文, $2010,30(4): 47-51$. ]

[18] Wang SJ, Yan YX, Yan M et al. Contributions of precipitation and human activities to the runoff change of the Huangfuchuan drainage basin: Application of comparative method of the slope changing ratio of cumulative quantity. Acta Geographica Sinica , 2012, 67(3) : 388-397. [王随继, 间云霞, 颜明等. 皇甫川流域降水和人类活动对径流量变化的贡献率 分析一一累积量斜率变化率比较方法的提出及应用. 地理学报, 2012, 67(3):388-397.]

[19] Zhao GJ, Mu XM, Jiao JY et al. Assessing response of sediment load variation to climate change and human activities with six different approaches. Science of the Total Environment, 2018, 639: 773-784. DOI: 10.1016/j. scitotenv.2018.05.154.

[20] Dey P, Mishra A. Separating the impacts of climate change and human activities on streamflow: A review of methodologies and critical assumptions. Journal of Hydrology, 2017, 548: 278-290. DOI: 10.1016/j.jhydrol.2017.03.014.

[21] Liu GH, Qi SH, Zhu JX et al. Quantitative estimation of runoff changes in Ganjiang River, Lake Poyang Basin under climate change and anthropogenic impacts. J Lake Sci, 2016, 28(3) : 682-690. DOI: 10.18307/2016.0326. [刘贵花, 齐 述华, 朱婧碹等. 气候变化和人类活动对鄱阳湖流域赣江径流影响的定量分析. 湖泊科学, 2016, 28(3): 682-690.]

[22] Shi P, Zhang Y, Ren ZP et al. Land-use changes and check dams reducing runoff and sediment yield on the Loess Plateau of China. Science of the Total Environment, 2019, 664: 984-994. DOI: 10.1016/j.scitotenv.2019.01.430.

[23] Zhao GJ, Kondolf GM, Mu XM et al. Sediment yield reduction associated with land use changes and check dams in a catchment of the Loess Plateau, China. CATENA, 2017, 148: 126-137. DOI: 10.1016/j.catena.2016.05.010.

[24] Guo LP, Mu XM, Hu JM et al. Assessing impacts of climate change and human activities on streamflow and sediment discharge in the Ganjiang River Basin (1964-2013). Water, 2019, 11(8) : 1679. DOI: 10.3390/w11081679.

[25] Gu CJ, Mu XM, Gao P et al. Variation of runoff and sediment discharge and response to human activities in the Ganjiang River. Journal of Sediment Research, 2016, (3) : 38-44. [顾朝军, 穆兴民, 高鹏等. 赣江流域径流量和输沙量的变 
化过程及其对人类活动的响应. 泥沙研究, 2016, (3) : 38-44.]

[26] Liu XG, Li CY, Wu DY. Changing characteristic and its impact factor analysis of streamflow and sediment of Ganjiang River Basin during past 60 years. Resources and Environment in the Yangtze Basin, 2015, 24(11) : 1920-1928. DOI: 10. 11870/cjlyzyyhj201511016. [刘星根, 李昌彦, 吴敦银. 近 60 年赣江水沙变化特征及影响因素分析. 长江流域资源 与环境, 2015, 24(11): 1920-1928.]

[27] Liu HY, Bai H. Contribution rate analysis of driving factors on the rainfall-sediment relationship of Zhangriver watershed in the upper region of Ganjiang watershed. Resources and Environment in the Yangtze Basin, 2018, 27(3) : 615-623. DOI: 10.11870/cjlyzyyhj201803017. [刘惠英, 白桦. 竷江上游章水流域水沙变化的驱动力分析. 长江流域资源与环境, $2018,27(3): 615-623$.

[28] Jiangxi Provincial Department of Resources ed. Jiangxi River and Lake Canon. Wuhan: Changjiang Press, 2010 : 1-581. [江西省水利厅. 江西河湖大典. 武汉: 长江出版社, 2010: 1-581.]

[29] Liang Y, Pan XZ, Sun B. Spatial and temporal variations of soil erosion in Xingguo County from 1958 to 2000. Bulletin of Soil and Water Conservation, 2006, 26(6) : 24-27, 71. [梁音, 潘贤章, 孙波. 42 年来兴国县土壤侵蚀时空变化规律 研究. 水土保持通报, 2006, 26(6): 24-27, 71.]

[30] Zhang XB, Vincent LA, Hogg WD et al. Temperature and precipitation trends in Canada during the 20th century. Atmosphere-Ocean, 2000, 38(3) : 395-429. DOI: 10.1080/07055900.2000.9649654.

[31] Sen PK. Estimates of the regression coefficient based on Kendall's tau. Journal of the American Statistical Association, 1968, 63(324) : 1379-1389. DOI: 10.1080/01621459.1968.10480934.

[32] Pettitt AN. A non-parametric approach to the change-point problem. Applied Statistics, 1979, 28(2): 126. DOI: 10. $2307 / 2346729$.

[33] Long YN, Tang R, Jiang CB et al. Variability characteristics of runoff-sediment discharge and their response to human activities in Xiang River basin in recent 60 years. Transactions of the Chinese Society of Agricultural Engineering, 2018,34 (24)：132-143. [隆院男, 唐蓉, 蒋昌波等. 近 60 年湘江流域水沙特性及其对人类活动的响应. 农业工程学报, $2018,34(24): 132-143$.

[34] Sun Q, Yu KX, Li ZB et al. The trends of streamflow and sediment and their driving factors in the middle reaches of the Yellow River. Acta Geographica Sinica, 2018, 73(5) : 945-956. DOI: 10.11821/dlxb201805013. [孙倩, 于坤霞, 李占 斌等. 黄河中游多沙粗沙区水沙变化趋势及其主控因素的贡献率. 地理学报, 2018, 73(5): 945-956.]

[35] Merriam CF. A comprehensive study of the rainfall on the Susquehanna Valley. Transactions, American Geophysical Union, 1937, 18(2) : 471. DOI: 10.1029/tr018i002p00471.

[36] Xie P, Wu ZY, Sang YF et al. Evaluation of the significance of abrupt changes in precipitation and runoff process in China. Journal of Hydrology, 2018, 560: 451-460. DOI: 10.1016/j.jhydrol.2018.02.036.

[37] Huang X, Fang NF, Shi ZH et al. Decoupling the effects of vegetation dynamics and climate variability on watershed hydrological characteristics on a monthly scale from subtropical China. Agriculture, Ecosystems \& Environment, 2019, 279 : 14-24. DOI: 10.1016/j.agee.2019.03.012.

[38 ] Guo LP, Yu Q, Gao P et al. Trend and change-point analysis of streamflow and sediment discharge of the Gongshui River in China during the last 60 years. Water, 2018, 10(9) : 1273. DOI: 10.3390/w10091273.

[39] Xu JL, Zhang Y, Zhang XB et al. Research on soil and water conservation achievements of benefits of runoff \& sedimentation reduction of the Shiwang River. Research of Soil and Water Conservation, 2014, 21(6) : 140-143, 147. [徐家隆, 张 云, 张雪兵等. 仕望河流域水土保持措施的减水减沙效益研究. 水土保持研究, 2014, 21(6): 140-143,147.]

[40] Wang YG, Shi HL, Liu X. Influence of sediment trapping in reservoirs on runoff and sediment discharge variations in Yangtze River. Advances in Water Science, 2014, 25(4) : 467-476. [王延贵, 史红玲, 刘茜. 水库拦沙对长江水沙态势变 化的影响. 水科学进展, 2014, 25(4): 467-476.

[41] Yang WG, Dai R, Zhang Y et al. Analysis of variations and causes in runoff and sediment of Yangtze River during 20002015. Science of Soil and Water Conservation, 2019, 17(1): 16-23. DOI: 10.16843/j.sswc.2019.01.003. [杨维鸽, 代 茹, 张雁等. 2000-2015 年长江干流水沙变化及成因分析. 中国水土保持科学, 2019, 17(1): 16-23.] 